\title{
Caregiver perceptions about the impact of caring for patients with wet age-related macular degeneration
}

M Vukicevic ${ }^{1}$, J Heraghty ${ }^{2}$, R Cummins², B Gopinath ${ }^{3}$ and P Mitchell ${ }^{3}$

\begin{abstract}
Purpose Caregivers of older persons with eye disease, namely age-related macular degeneration (AMD), have been reported to have a higher than expected distress. Very few studies have explored caregiver perceptions as to what is important when providing care. The aim of this study was to explore the perceptions of caregivers of persons with neovascular AMD in relation to the most important aspects of caring, as described in extended answers to selfadministered survey questions. Methods A cross-sectional, self-administered survey of 643 caregivers of people with neovascular AMD, comprising 27 closed-response questions and 2 open ended questions. The latter were analysed as part of this study utilising and 'inductive' Grounded Theory approach.
\end{abstract} Results Six-hundred and forty-three caregiver responses to 2 open ended questions were analysed using an inductive approach and sorted into thematic networks. Three discrete categories arose: The Impact of Caring; Injections and Information and Activities of Daily Living. Conclusions Most caregivers were family caregivers and were found to be compassionate and self-sacrificing. They accepted additional responsibility whilst providing an encouraging environment for their care recipient. As a result, they experience distress and consider their own needs as secondary. Very few seek or receive respite and this added burden can have a negative impact upon the relationship between caregiver and care recipient. Eye (2016) 30, 413-421; doi:10.1038/eye.2015.235; published online 27 November 2015

\section{Introduction}

As a result of an increased ageing population, patients with chronic diseases are often cared for by family members who provide informal care outside of hospital or institutional care. The role of these family members as primary caregivers is extensive and they provide various types of assistance to the care recipient, including: daily living tasks; support at medical appointments; ensuring medication compliance; and also emotional support. Family caregivers often provide assistance without formal training yet despite this, there is a high expectation that caregivers will provide competent care both in the home and in the medical setting. ${ }^{1-3}$

Family caregivers are usually not compensated for their time and in addition, tend to neglect their own personal needs. It is well documented that caregiver burden includes expending significant financial, emotional and physical effort while receiving no return (both financial and emotional). This in turn causes overload and stress compromising the caregiver's health and quality of life. ${ }^{1-5}$ The burden caregivers experience may be related to their demographic and social factors (age, race, gender, education and so on) and poor patient health outcomes arise when the health of caregivers is compromised and inadequate resources are available to assist the care recipient. ${ }^{3,4}$

Of particular interest is the impact of caring for people with vision impairment, particularly those with age-related macular degeneration (AMD). AMD affects central vision and impacts fine detailed visual tasks such as reading, daily living activities and driving and so on. ${ }^{6-8}$ The prevalence of AMD across the developed world is markedly increasing owing to the ageing population. The resultant burden of this disease is well established. ${ }^{6-9}$

Caregivers of older persons with AMD have higher than expected distress, particularly if the person has 'wet' AMD. 3,5 The principal cause of vision loss in wet AMD is choroidal
${ }^{1}$ Discipline of Orthoptics, School of Allied Health, Department of Clinical and Community Allied Health, La Trobe University, Melbourne, VIC, Australia

${ }^{2}$ Macular Disease Foundation Australia, Sydney, NSW, Australia

${ }^{3}$ Department of Ophthalmology and Westmead Millennium Institute, University of Sydney, Sydney, NSW, Australia

Correspondence: M Vukicevic, Discipline of Orthoptics, School of Allied Health, College of Science Health and Engineering, La Trobe University, Melbourne 3086, VIC, Australia

Tel: +61 39479 1807;

Fax: +61 394793692 E-mail:m.vukicevic@ latrobe.edu.au

Received: 24 August 2015 Accepted in revised form: 29 September 2015 Published online: 27 November 2015 
neovascularisation. This form of AMD constitutes only $10-15 \%$ of cases but vision loss, particularly if left untreated, is marked. Currently, wet AMD is treated with intravitreal injections of antiangiogenic drugs that target vascular endothelial growth factor (VEGF). The treatment regimen is rigorous with patients typically requiring three initial injections given at four weekly intervals, followed by ongoing injections every 4-12 weeks, with the interval determined by individual response. ${ }^{3,10}$ Pain and anxiety related to anti-VEGF injections has also been reported. ${ }^{10}$ Many people with AMD rely on family caregivers to accompany them to intravitreal injection clinics and escort them home, in addition to providing ongoing assistance in the first $24 \mathrm{~h}$ after treatment. The burden experienced by caregivers is associated with the amount of vision impairment experienced by the patient and therefore the resultant assistance they require. ${ }^{5}$

Although caregiver burden and distress has been studied, few studies have explored caregiver perceptions as to what they consider important when providing care. Important factors include the necessary attributes required for caring, namely compassion, patience, and selflessness. Compassion is defined as the feeling for another's sorrow or hardship that leads to help, pity or sympathy' ${ }^{11}$ A compassionate person considers the suffering of others and tries to alleviate it. This in turn can lead to compassion fatigue whereby the caregiver experiences stress and strain while caring for a person with illness. Compassion is particularly acute when bonds (ie, kinship or affection) are present between two people; the caregiver is aware of a person's hardship and is therefore motivated to reduce it. Mostly caregiver motivation is purely altruistic and their primary goal is to help the care recipient, which is often at their own expense. This arises out of love, concern, or responsibility felt toward the care recipient. ${ }^{12}$ The level of compassion may impact on the health of the caregiver, in that if the care recipient's difficulties cannot be relieved, then this is experienced as a negative health impact and becomes stressful. The level of compassion is not, however, impacted by the amount of stress experienced by the caregiver. Generally an increase in care recipient hardship requires an increase in compassion shown by the carer. ${ }^{12,13}$

Caregiver perceptions and self-reflections, including the attribute of compassion, are important to consider. Studies have indicated that hospital patients treated by a compassionate caregiver share more information about their symptoms. This leads to better understanding of their health concern and in turn more accurate diagnosis and treatment. ${ }^{14-16}$ It is likely that this also applies to situations of informal or family caregiving, but to our knowledge, no studies have investigated the impact of caring as it relates to personality attributes such as compassion and empathy. The aim of this study was to explore the perceptions of caregivers in relation to the most important aspects of caring, as described by their extended responses to two questions:

1. Do you have any other comments about caring for someone with wet AMD that you believe are important for other people to know and understand?

2. What are the three most important aspects of caring for someone with wet AMD for you?

\section{Materials and methods}

\section{Study design and sample}

This study was conducted by the Macular Disease Foundation Australia (MDFA) and administered by the MDFA and Galaxy Research. Three thousand one hundred and seventy people on the MDF database listed as having wet AMD were invited to participate. A slightly different survey was also included in the distribution, for completion by the patient's caregiver. In addition, 3282 people on the MDFA database listed as a family member or caregiver of someone with AMD were sent the caregiver survey. For this study a caregiver was defined as anyone providing care and support to a person with wet AMD, including spouse or partner, family member, friend, and paid care worker.

Both the patient and caregiver surveys were crosssectional and self-administered. The patient survey comprised 38 items whilst the caregiver survey contained 29 items. Structured demographic questions and those requiring Likert-scale responses were included in both surveys, in addition to two extended response questions.

Survey responses were anonymous and did not include identifiers. Participants gave informed consent and post hoc, counterfactual approval was obtained from the Bellberry Human Research Ethics Committee.

A total of 1160 patient and 643 caregiver surveys were returned. The responses of the first 500 patients with wet AMD and 500 caregivers received were included in the first analysis with the focus being on caregiver distress extrapolated from the structured caregiver questions. The results of these findings have been published. ${ }^{5}$ The extended response questions provided by caregivers were not included in the findings published by Gopinath ${ }^{5}$ but were analysed separately, in this study.

\section{Statistical analysis}

Caregiver extended responses were coded and analysed using NVivo (QSR International, Doncaster, VIC, Australia). An 'inductive' approach was utilised to 
analyse the data whereby the data itself determine the structure of the analysis with no predetermined theory. Thematic networks (web-like illustrations with no hierarchy) were then created to summarise the main themes, thus a Grounded Theory approach was applied. ${ }^{17}$ Six thematic networks evolved from the carer statements, each with their own set of organising themes (clusters of similar issues) and basic themes (ideas presented within organising themes, but on their own are meaningless). ${ }^{17}$

Links were made between the thematic networks to create three discrete categories: (i) The Impact of Caring; (ii) Injections and Information; and (iii) Activities of Daily Living.

Caregiver demographic data were analysed using IBM SPSS Statistics 22 (IBM Corporation, Armonk, NY, USA).

\section{Results}

Responses were received for 643 caregivers. The age distribution of caregivers and care recipients is shown in Figure 1. The gender distribution of both caregivers and care recipients was disproportionately skewed towards a higher number of females. Question response rate, gender, caregiver type, and level of care recipient dependence are described in Table 1.

Three discrete thematic networks were extrapolated from the data: (i) The Impact of Caring; (ii) Injections and Information; and (iii) Activities of Daily Living. These discrete thematic networks were further divided into sub, organising, and basic themes (Table 2).

A total of 1342 responses were coded. The largest number of responses (63\%) were categorised within The Impact of Caring thematic network. Results from the structured caregiver questions indicate that caregivers experience significant psychological distress and a disrupted lifestyle. They neglect their own needs and caring impacts upon their relationships and their retirement plans. ${ }^{5}$ These caregivers had higher than expected levels of distress and whereas several predictors were identified from the quantitative data, this thematic analysis of the extended responses contributes to a better understanding as to why. This is particularly pertinent for this category related to The Impact of Caring.

\section{The impact of caring}

Carer attributes The Carer Attributes sub-theme explores the attributes caregivers identify as being important for caring for someone with wet AMD such as compassion, encouragement, and patience that highlights their selfless attitude. The emergent themes relate to the requirement of being compassionate as a caregiver (together with having patience), creating an encouraging environment and fostering independence. The negative effect of being compassionate and showing empathy is self-sacrifice. Caregivers give up their independence and absorb additional responsibility which can affect the relationship between the caregiver and care recipient.

Illustrative examples of caregiver responses related to this The Impact of Caring thematic network are listed in Table 3a.

Many caregivers identify compassion as an important aspect to looking after another person and these types of statements appeared more frequently than any others.

In order to care for someone with wet AMD you need to understand their eye condition and both the physical and emotional impact this has on their well-being. The ability to be patient with the person you are caring for in terms of both their physical disability and emotional state was highlighted as a desirable quality and linked closely with the quality of compassion. Empathy was also strongly represented, with caregivers indicating that one needs to put themselves in the shoes of the care recipient when caring.

It appears that compassion extends beyond empathy and leads to an active response from the carer propelling

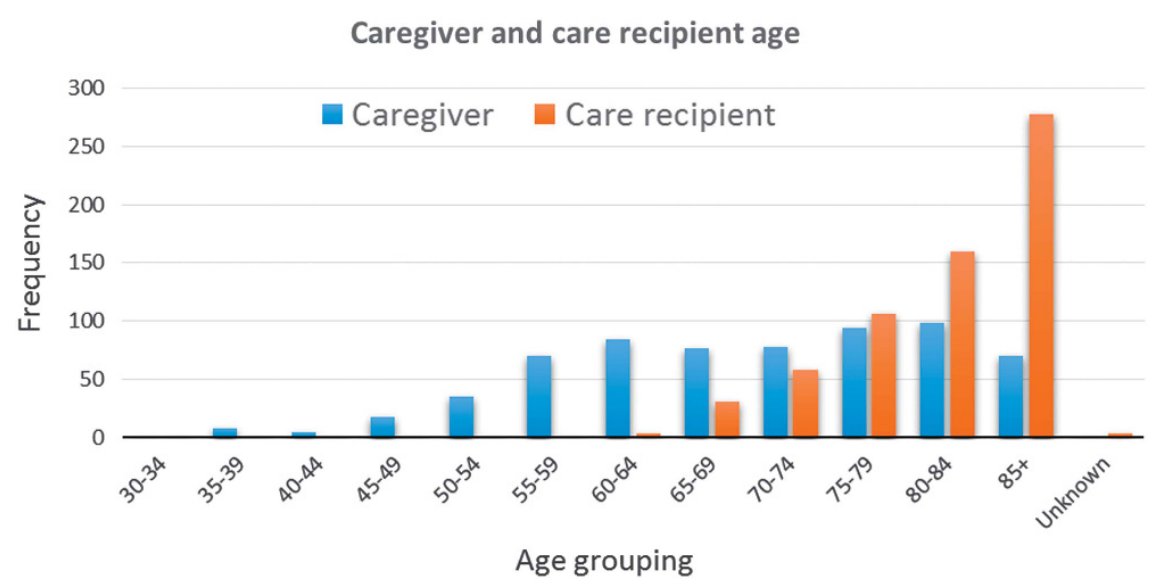

Figure 1 Age distribution of caregivers and care recipients. 
Table 1 Caregiver and care recipient demographic information

\begin{tabular}{lll}
\hline & Caregiver & Care recipient \\
\hline $\begin{array}{ll}\text { Extended answer questions, } \\
\text { Response rate }\end{array}$ & $\begin{array}{l}\text { Question 1: } 348(54 \%) \\
\text { Question 2: } 457(71 \%)\end{array}$ & Female: $n=396(61 \%)$ \\
Gender & Female: $n=409(64 \%)$ & Male: $n=243(38 \%)$ \\
& Male: $n=215(33 \%)$ & Unknown: $n=4(1 \%)$
\end{tabular}

them to provide emotional encouragement. The need for positive reassurance by the caregiver to the care recipient was seen as elementary. In this context, a positive caregiver attitude was fundamental to emotional encouragement of the recipient. The structured question responses suggest that caregivers experience emotional distress. ${ }^{5}$ However, the extended responses indicate that caregivers tend to limit the outward expression of this distress for the positive benefit of the care recipient. An underlying tone to the caregivers' comments related to avoiding patient depression and this was often mentioned.

Relatively few statements were made with reference to caregiver's needs. Most of the comments related to needing a break from caring and the statements emphasise the importance of respite from caring and are for that reason, worth mentioning.

Awareness of the needs of the care recipient is evidenced by statements, which encourage their independence. Caregiver statements reflect that they recognised the fine line between allowing the care recipient to be independent, but instinctively wanting to step in and do take on tasks for them without being asked.

Sacrifices made This sub-theme provides a complete narrative and insight into how the daily lives of caregivers are affected. Issues arise in consequence to the additional responsibility involved with caring and the end result is significant sacrifice made by the caregiver in order to meet the needs of the care recipient. Caregiver attributes such as empathy and compassion speak to the nature of the person. These traits therefore naturally lead to self-sacrifice for the benefit of another.

Two major narratives related to responsibility emerged; the first is an expression of constant concern for the care recipient. The second relates to ongoing responsibility which fuels the worry experienced by carers, mostly in terms of the safety of the care recipient. Concern for the care recipient combined with additional domestic duties impact upon the caregiver's time, which they sacrifice. There is less time for the caregiver's own needs and this in turn affects their independence.

Despite the ongoing worry and significant sacrifices being made by caregivers to assist the care recipient, some caregivers made statements regarding issues related to guilt. This may be in circumstances where the caregiver is not in a position to extend care to the care recipient for every aspect of their daily life.

Impact on relationship Additional caregiver responsibility, increased distress and so on compromises the relationship between the caregiver and recipient and this was found to be either positive or negative, with clear delineation between the two. For example, statements made by carers either explained the negative impact on the relationship or the positive, but never a combination.

Caregivers perceived that care recipients showed increased sensitivity to, for example: criticism, being patronised, not being able to see things pointed out to them and so on. Caregivers perceived a change in the relationship with an increased emotional strain and some suggested their care recipient was manipulative 
Table 2 Extrapolation of the Thematic Network sub-themes, organising themes and basic themes

\begin{tabular}{|c|c|c|}
\hline Sub-theme & $\begin{array}{l}\text { Organising theme } \\
\text { (Clusters of similar issues) }\end{array}$ & $\begin{array}{l}\text { Basic theme } \\
\text { (Ideas within organising themes, meaningless on their own) }\end{array}$ \\
\hline \multicolumn{3}{|c|}{ Thematic network: The Impact of Caring } \\
\hline \multirow{3}{*}{ Carer Attributes } & Ability to foster independence & $\begin{array}{l}\text { Encourage independence } \\
\text { Allow independence by monitoring own behaviour } \\
\text { Let the patient ask for help }\end{array}$ \\
\hline & Emotional Encouragement & $\begin{array}{l}\text { Encourage patient to deal with eye condition } \\
\text { Avoid depression in patient by keeping positive attitude }\end{array}$ \\
\hline & Carer's needs & $\begin{array}{l}\text { Time off from caring is important } \\
\text { Social contacts are essential for health and well-being }\end{array}$ \\
\hline \multirow[t]{6}{*}{ Sacrifices Made } & Time & Less time for carer's needs \\
\hline & Worry & $\begin{array}{l}\text { Carers worry about the future, the care recipient, finances, vision etc. } \\
\text { Constant concern for the patient }\end{array}$ \\
\hline & Independence & Carer's independence is affected \\
\hline & Additional responsibility & $\begin{array}{l}\text { Carer has to drive } \\
\text { Increase in domestic tasks } \\
\text { Carers go without because finances are impacted }\end{array}$ \\
\hline & Holidays and leisure activities & $\begin{array}{l}\text { Holidays and retirement plans are affected } \\
\text { Time with friends is affected }\end{array}$ \\
\hline & Guilt & Carer feels guilty if they are not there all the time \\
\hline $\begin{array}{l}\text { Impact on } \\
\text { Relationship }\end{array}$ & Positive & $\begin{array}{l}\text { Caring can positively enhance a relationship } \\
\text { Strong bonds between the carer and patient form } \\
\text { Positive impact usually occurs between spouses/domestic partners }\end{array}$ \\
\hline \multicolumn{3}{|c|}{ Thematic network: Injections and Information } \\
\hline \multirow[t]{4}{*}{ Injections } & Advice to others & $\begin{array}{l}\text { Early treatment for AMD is crucial and everyone needs regular eye } \\
\text { examinations } \\
\text { Ensure the patient maintains treatment protocol } \\
\text { Inform family members and advise them to have an eye examination }\end{array}$ \\
\hline & Pain or anxiety & $\begin{array}{l}\text { Patients get anxious about eye injections } \\
\text { Pain is often a factor }\end{array}$ \\
\hline & Cost & $\begin{array}{l}\text { Treatment is expensive } \\
\text { More subsidy is required for cost of treatment }\end{array}$ \\
\hline & Travel & $\begin{array}{l}\text { The burden of injections is increased if travelling considerable distance to } \\
\text { receive treatment }\end{array}$ \\
\hline \multirow[t]{2}{*}{ Information } & Eye care staff and the public & $\begin{array}{l}\text { Staff in care facilities and eye clinics seem unaware of the impact of AMD } \\
\text { The public is has limited awareness of the impact of AMD on sight }\end{array}$ \\
\hline & Carers & $\begin{array}{l}\text { Carers need to inform themselves about AMD and its impact } \\
\text { Support services are helpful for carers who need more information } \\
\text { about AMD }\end{array}$ \\
\hline Thematic network: & $\begin{array}{l}\text { vities of Daily Living } \\
\text { Fine detail vision }\end{array}$ & $\begin{array}{l}\text { Difficulty reading affects most home activities } \\
\text { People with AMD struggle to read and need assistance } \\
\text { Use of technology is helpful }\end{array}$ \\
\hline & Mobility & $\begin{array}{l}\text { Modify the home to limit impact on mobility } \\
\text { Encourage outings but be aware of patient limitations }\end{array}$ \\
\hline & Hygiene and grooming & Extra assistance is required as AMD affects this \\
\hline & Driving & $\begin{array}{l}\text { Carers take on the burden of driving } \\
\text { Patients become frustrated when they can no longer drive }\end{array}$ \\
\hline
\end{tabular}


Table 3a Illustrative examples of participant quotes for The Impact of Caring thematic analysis

Thematic network: The Impact of Caring

Total number of quotes for this thematic network: $\mathrm{n}=845$

$\begin{array}{ll}\text { Sub-theme } & \text { Nor sub-theme of responses } \\ \end{array}$

Carer attributes $n=521(62 \%) \quad$ Carer \#272 (Female 70-74 years, caring for independent male 75-79 years):

'You are their eyes. Be patient. Be understanding of their frustration to depend on someone else doing things for them'

Carer \#346 (Female 50-59 years, caring for independent male 70-74 years):

'It is very important for the carer to fully appreciate the devastating impact that wet AMD has on the life of the person for whom one is caring. Put yourself in their shoes-imagine yourself with impaired vision. Be very patient, be kind all the time, be on hand at all times to help when needed-your call will be rewarded'

Carer \#181 (Female 50-59 years caring for moderately dependent female 70-79 years):

'Just to keep encouraging them and not to let it get them down. Stay positive.'

Carer \#157 (Male 70-74 years caring for somewhat dependant female 65-69 years):

'It is important to get regular time off from being a carer'

Carer \#578 (Male 85 years and over, caring for moderately dependent female 85 years and over):

'It is very difficult to walk the fine line between helping and dominating'

Sacrifices made $n=268(31 \%) \quad$ Carer \#12 (Male of unknown age, caring for independent female 80-84 years)

'When I am away playing bowls I feel the need to telephone home often to see that the spouse is $\mathrm{OK}^{\prime}$

Carer \#7 (Female 65-69 years caring for female 85 years and over, dependence level unknown) 'As a carer, particularly for someone who has vision loss, your own independence is reduced as you are no longer free to come and go as you please'

Carer \#335 (Female 45-49 years caring for extremely dependent female 80-84)

'Feeling guilty about not being there for their everyday needs. Feeling sad about their loss of independence and having to rely upon the availability of someone else. When there is only one person to rely on, they [the carer] feel a burden'

Impact on $\quad n=56(7 \%)$ relationship Carer \#71 (Female 65-69 years caring for female 85 years and over, dependence level unknown)

'They are very aware of the impact they are having on family and friends and are sensitive to being patronised and being treated as helpless'

Carer \# 546 (Female 65-69 years caring for extremely dependent male 85 years and over)

'Be aware of manipulation, (the) person can be very demanding'

Carer \#481 (Female 65-69 years caring for very dependant male 85 years and over)

'We have been married over 50 years and care for each other equally.............. in a loving, mature, long lasting partnership you just get on with being a carer without a thought or regret' Carer \#8 (Male 80-84 years caring for somewhat dependent female 70-74 years)

'[I] give my wife any time I have, tell her my love is for her [and] try not to scold her anytime'

(and aware of being so) leading to feelings of guilt by the caregiver.

Most statements related to a negative impact on the relationship appear to be when the caregiver is not the spouse/domestic partner of the care recipient. The opposite is true when the caregiver and recipient are in a relationship. In this case, caring brings the two people closer together.

\section{Injections and information}

The Injections and Information thematic network comprised $17 \%$ of responses. A distinction was made between caregiver comments related to Injections and Information and both are presented separately (Table 3b).
Injections With respect to treatment injections received by the care recipient, caregivers offer advice to others, describe the pain and anxiety experienced by the patient, and express their concern regarding the cost of treatment. A small number of statements related to difficulty with travelling for treatment were made, particularly if caregivers lived outside of larger cities.

Caregivers identify that the need for early treatment for wet AMD is crucial, as is the continuity of the treatment protocol prescribed by the care recipient's ophthalmologist.

In addition, caregivers raise the importance of regular eye examinations not only for the care recipient but for all members of the family, with particular emphasis on informing family members that AMD has a genetic component and therefore that they may be affected. This 
Table $3 \mathbf{b}$ Illustrative examples of participant quotes for the Injections and Information thematic analysis

\begin{tabular}{|c|c|c|}
\hline \multicolumn{3}{|c|}{$\begin{array}{l}\text { Thematic network: Injections and Information } \\
\text { Total number of quotes for this thematic network: } \mathrm{n}=229\end{array}$} \\
\hline Sub-theme & $\begin{array}{l}\text { Number of responses for } \\
\text { sub-theme }\end{array}$ & Participant quotes \\
\hline \multirow[t]{8}{*}{ Injections } & \multirow[t]{8}{*}{$n=229(64 \%)$} & Carer \#142 (gender and age of carer and patient unknown) \\
\hline & & $\begin{array}{l}\text { 'Important to be monitored and diagnosed early to access treatment to stop if possible progress of } \\
\text { disease. Important to be educated and be aware of risk and contributing factors' }\end{array}$ \\
\hline & & Carer \#422 (Female 70-74 years caring for moderately dependent male 80-84 years) \\
\hline & & 'I feel useless when patient is in severe pain' \\
\hline & & Carer \#146 (Female 75-79 years caring for somewhat dependent male 80-84 years) \\
\hline & & 'Should be more help available. Very expensive treatment' \\
\hline & & Carer \#206 (Female 80-84 years caring for moderately dependent female 85 years and over) \\
\hline & & $\begin{array}{l}\text { 'There is little understanding by health professionals, especially ophthalmologists of difficulties } \\
\text { faced by patients. Requiring payment, for an old person usually cash of approx. } \$ 500-\$ 600 \text { at time } \\
\text { of appointment' }\end{array}$ \\
\hline \multirow[t]{9}{*}{ Information } & \multirow[t]{9}{*}{$n=82(36 \%)$} & Carer \#24 (Female 65-69 years caring for male 65-69 years, unknown dependence level) \\
\hline & & 'I feel more people should get to know and learn more about what happens to people with AMD \\
\hline & & and how to help them as some people are unaware of how it impacts on these peoples' lives. They \\
\hline & & $\begin{array}{l}\text { do not realise or are unaware of the problems associated with AMD of any kind. I feel very } \\
\text { inadequate myself as the needs of these people affected can worsen as time goes on' }\end{array}$ \\
\hline & & Carer \#209 (Female 65-69 years caring for extremely dependent female 85 years and over) \\
\hline & & 'Much of the general public do not understand the demands put upon carers of people with wet \\
\hline & & AMD or how difficult it is for AMD patients to cope outside their own home!' \\
\hline & & Carer \#420 (Female 75-79 years caring for moderately dependent male 80-84 years) \\
\hline & & $\begin{array}{l}\text { 'It is surprising that staff, including administration, have very little idea on many simple things } \\
\text { that make mobility difficult e.g. small occasional tables placed in centre of room below vision } \\
\text { level and in way of where he walks etc.' }\end{array}$ \\
\hline
\end{tabular}

Table 3c Illustrative examples of participant quotes for the Activities of Daily Living thematic analysis

Thematic network: Activities of Daily Living

Total number of quotes for this thematic network: $\mathrm{n}=268$

Participant quotes

Carer \#328 (Male 65-69 years caring for extremely dependent female 85 years and over)

'Mum does not feel comfortable in public and worries that because she cannot see people's faces properly, she does not read their expressions and cannot respond accordingly. She thinks that they may think she is rude as her eyes and presentation are completely normal'

Carer \#33 (Female 80-84 years caring for female 80-84 years, dependence level unknown)

'You must watch where they are walking and describe obstacles to them'

Carer \#83 (Female 85 years and over caring for male 85 years and over, dependence level unknown)

'I find it hard being the driver'

extension of concern to other family members, particularly younger ones, is aligned with the general expression of concern for others, inherent in caregivers.

Caregivers report that care recipients become anxious about upcoming injections and that pain is a factor. The issue of compassion, described previously is again reiterated with regards to empathising with the person who is experiencing the pain.

The opinion that treatment injections were expensive was referred to by only 22 caregivers in this study, therefore obviously carers perceived other issues to be more important. However, these statements are worthwhile reporting particularly as there is a belief that additional subsidies should be provided for patients undergoing treatment injections. Similarly, the problem of travelling long distances to receive treatment was only stated seven times, but like cost, caregivers that highlighted this issue found it particularly onerous and an overall burden.

Information Caregivers express their concern that information is lacking or limited for them, particularly in relation to the topic of caring and receiving support, in 
addition to information about wet AMD and how to help their care recipient manage it. This is of particular interest, as the caregivers surveyed were known clients of MDFA and it are likely to be better informed than other care givers of people with wet AMD. The statements also raise the concern that others (friends, the public, clinic staff and so on) seem to not understand AMD.

Some caregivers had the perception that eye clinic staff and ophthalmologists were not aware of the impact of AMD upon daily living tasks and insensitive to the needs of patients, despite being at the front line of treatment.

\section{Activities of daily living}

The results from the closed-response survey questions shows that caregivers assist with groceries, finances, cleaning, cooking, and mobility ${ }^{5}$ and this is consistent with comments caregivers made in the extended responses.

This thematic network represents the issue that vision impairment impacts the day to day tasks performed by care recipients. Caregivers report that care recipients struggle with fine detail vision (ie, reading or recognising faces), mobility, hygiene/grooming, and driving (Table 3c). Overall, 20\% of comments related to this theme.

Caregivers are also concerned that the care recipient was misunderstood by others who do not understand the impact of AMD upon fine, detailed vision. The need to be mindful of the care recipient's surroundings, to avoid obstacles within and outside the home (eg, chairs, uneven surfaces, steps) and to act as a mobility guide were described by caregivers as important factors.

Caregivers also describe the distress care recipients experience at no longer being able to drive. The flow on effect is the added burden on the caregiver to provide transport, taking on the additional burden of driving where this was previously shared, or utilising unfamiliar modes of transport.

According to the issues raised within this thematic network, generally wet AMD has a significant impact on several aspect of daily living and these are all a direct result of loss of ability to discern fine details.

\section{Discussion}

Taking on the duty of caring for another person is not something everyone is able to do and the tasks the caregivers in this study perform for their care recipients are consistent with those previously reported. ${ }^{3,6-8}$ The personality traits of a caregiver, as evidenced by this study, include compassion; self-sacrifice; ability to accept additional responsibility; and provide a positive and encouraging environment. This requires a significant degree of commitment by the caregiver and historically, developing a 'compassionate character', for example, in Florence Nightingale's view, specifically underpinned quality of nursing care. ${ }^{13}$ These personality traits, combined with the level of commitment demonstrated by caregivers of patients with wet AMD could be an additional reason for generally increased distress reported in the literature. Therefore, increased distress may not only be related to factors such as demographic attributes of caregivers, the time they spend caring, the dependence level or amount of vision impairment of the care recipient. ${ }^{1-5}$ The caregiver statements identified in this study clearly speak to the selfless nature of these caregivers.

Most of the caregivers in this study were family caregivers and this is consistent with another study reporting a high rate of informal caregiving for patients with wet AMD. ${ }^{3}$ The statements related to Carer Attributes highlight the selflessness demonstrated by caregivers and their primary focus is on easing the burden for the care recipient and having compassion for that person's circumstances while neglecting their own needs. This is consistent with studies reporting the compromise to caregivers' health and quality of life. ${ }^{1-4}$ Taking a break from caring or seeking an alternate social outlet could be perceived as selfish and caregivers may be reluctant to express this, however, a few caregivers did raise this issue that others were more reticent to express, because inherently they are selfless by nature. The known psychological distress experienced by caregivers and disruption to lifestyle could be lessened if caregivers themselves received respite. The emotion of guilt is expressed by caregivers in this study and while they make sacrifices, they can experience guilt; guilt impacts upon the relationship between the caregiver and recipient, particularly if the care recipient is perceived to be actively manipulative.

Although the caregiver burden related to assisting the care recipient with medical treatment, namely antiVEGF injections, has been reported, ${ }^{3}$ the experience and inner thoughts of caregivers has not. The findings of this study highlight issues related to empathy when the care recipient experiences pain or anxiety; the ongoing costs of treatment (both direct and indirect) and the perception that information is limited, despite the fact that these caregivers are registered with the MDFA and receive ongoing and regularly updated information.

What does the answer to these two extended response questions tell us about the perceptions of caregivers of people with wet AMD? The answer is that caregivers are incredibly compassionate and patient people who are able to provide encouragement and promote independence in their care recipient. They take on additional responsibility (domestic duties, assisting with 
mobility, transport, tasks that require fine detail vision) yet sacrifice their own needs. Despite many studies reporting caregiver stress and the burden placed on caregivers, ${ }^{1-5,12}$ in this study, surprisingly, the caregivers did not identify these factors as being the most important aspects of caring for someone with wet AMD. Instead the focus was on the altruistic personality traits related to compassion, empathy and self-sacrifice. Caregivers experience a constant emotional concern towards their care recipient and admit that caring can be difficult, invariably leading to a negative impact upon the relationship between caregiver and recipient. However, the relationship can also be strengthened, particularly if the patient-carer relationship is a spouse/ domestic-partner one. This outcome is similar to that reported by Gohil ${ }^{3}$ whereby caregivers that were friends or spouses of the care recipient experienced a lower burden compared with sibling or offspring caregivers.

The findings of this study reveal an interesting and unexpected narrative into the lives of caregivers. It is quite evident that caregivers are very special people and require more support than currently available to them to prevent or ease the known issue of distress experienced as a result of caring. Further research is required to determine how best to meet the needs of caregivers efficiently and effectively.

\section{Summary}

What was known before

- It is well documented that caregiver burden includes expending significant financial, emotional and physical effort whilst receiving no return.

- This in turn causes overload and stress compromising the caregiver's health and quality of life.

- Caregivers of older persons with AMD have higher than expected distress, particularly if the person has neovascular AMD.

What this study adds

- Few studies have explored caregiver perceptions as to what they consider important when providing care.

- Important factors include the necessary attributes required for caring, namely compassion, patience and selflessness explored in this study.

- The caregiver experience related to assisting the care recipient with medical treatment, namely anti-VEGF injections, has not previously been reported.

- The findings of this study highlight issues experienced by care givers when caring for those with neovascular AMD.

\section{Conflict of interest}

The authors declare no conflict of interest.

\section{Acknowledgements}

Funding for this survey and data analysis was provided by Bayer Australia, Macular Disease Foundation Australia, and Orthoptics Australia.

\section{References}

1 Bambara J, Owsley C, Wadley V, Martin R, Porter C, Dreer L. Family caregiver social problem-solving abilities and adjustment to caring for a relative with vision loss. Invest Ophthalmol Vis Sci 2009; 50(4): 1585-1592.

2 Bialon L, Coke S. A study on caregiver burden: stressors, challenges and possible solutions. Am J Hosp Palliat Care 2012; 29(3): 210-218.

3 Gohil R, Crosby-Nwaobi R, Forbes A, Burton B, Hykin P, Sivaprasad S. Caregiver burden in patients receiving Ranibizumab therapy for neovascular age related macular degeneration. PLoS One 2015; 10(6): e0129361.

4 Cain C, Wicks M. Caregiver attributes as correlates of burden in family caregivers coping with chronic obstructive pulmonary disease. J Fam Nurs 2000; 6(1): 46-68.

5 Gopinath B, Kifley A, Cummins R, Heraghty J, Mitchell P. Predictors of psychological distress in caregivers of older persons with wet age-related macular degeneration. Aging Ment Health 2014; 19(3): 239-246.

6 Cahill M, Banks A, Stinnett S, Toth C. Vision-related quality of life in patients with bilateral severe age-related macular degeneration. Ophthalmology 2005; 112: 152-158.

7 Dong L, Childs A, Mangione C, Bass E, Bressler N, Hawkins B et al. Health-and vision-related quality of life among patients with choroidal neovascularization secondary to age-related macular degeneration at enrollment in randomized trials of submacular surgery. Am J Ophthalmol 2004; 138(1): 91-108.

8 Hassell J, Lamoureux E, Keeffe J. Impact of age related macular degeneration on quality of life. British Journal of Ophthalmology. 2006; 90(5): 593-596.

9 Mitchell J, Bradley C. Quality of life in age-related macular degeneration: a review of the literature. Health Qual Life Outcomes 2006; 4: 97.

10 Boyle J, Vukicevic M, Koklanis C, Itsiopoulos C. Experiences of patients undergoing anti-VEGF treatment for neovascular age-related macular degeneration: a systematic review. Psychol Health Med 2015; 20(3): 296-310.

11 Barnhart C, Barnhart R (eds). The World Book dictionary. Field Enterprises Educational Corporation: Chicago, IL, USA, 1996.

12 Schulz R, Hebert R, Dew M, Brown S, Scheier M, Beach S et al. Patient suffering and caregiver compassion: new opportunities for research, practice and policy. Gerontologist 2007; 47(1): 4-13.

13 Bradshaw A. Compassion: what history teaches us. Nurs Times 2011; 107(19): 12-14.

14 Cole-King A, Harding K. Psychological factos and delayed healing in chronic wounds. Psychosom Med 2001; 63(2): 216-220.

15 Cornwell J, Goodrich J. Ensuring compassionate care in hospital. Nurs Times 2009; 105(15): 14-16.

16 Epstein R, Franks P, Shields C, Meldrum S, Millier K, Campbell $\mathrm{T}$ et al. Patient-centred communication and diagnostic testing. Ann Fam Med 2005; 3(5): 415-421.

17 Attride-Stirling J. Thematic networks: an analytic tool for qualitative research. Qual Res 2001; 1(3): 385-405. 